\title{
RELAÇÃO DA CONEXÃO "EU-DEUS" EM PACIENTES PORTADORES DE CÂNCER
}

\section{ARTIGO DE REVISÃo}

OLIVEIRA, Vanessa Cristina de Castro Aragão ${ }^{1}$

CORREIA, Kharla Lettícia de Castro Loiola ${ }^{2}$

LEAL, Jamile Costa ${ }^{3}$

MACÊDO, Maria Gabriela Luz ${ }^{4}$

OLIVEIRA, Vanessa Cristina de Castro Aragão. Et al. Relação da conexão "EuDeus" em pacientes portadores de câncer. Revista Científica Multidisciplinar Núcleo do Conhecimento. Ano 05, Ed. 11, Vol. 11, pp. 42-55. Novembro de 2020. ISSN: 2448-0959, Link de acesso:https://www.nucleodoconhecimento.com.br/saude/portadores-de-cancer

\section{RESUMO}

Este trabalho trata-se de uma revisão de literatura que aborda temas relacionados a um senso de conexão com um ser de natureza superior pelos portadores de câncer. Objetivo: buscar a relação de conexão "Eu-Deus" em pacientes portadores de câncer. Metodologia: As buscas foram realizadas a partir de publicações indexadas nas bases de dados Scielo, Lilacs e Medline, cruzando os termos: câncer/espiritualidade/saúde, cancer/spirituality/health e cáncer/espiritualidad/salud. A pesquisa foi limitada aos idiomas inglês, português e espanhol, de 2015 a 2020, durante o período de setembro/2019 a junho/2020. Foram localizados 934 artigos dos quais sete

\footnotetext{
${ }^{1}$ Doutora em Saúde Pública.

2 Acadêmica Do Curso De Medicina.

${ }^{3}$ Acadêmica Do Curso De Medicina.

${ }^{4}$ Acadêmica Do Curso De Medicina.
} 
investigações constituíram a seleção final por atender o objetivo do estudo. As análises para a seleção dos artigos ocorreram em três etapas distintas. A primeira fase foi realizada pelas pesquisadoras, tendo como base os subsídios fornecidos pelo título e palavras-chave, a segunda, passou-se à leitura dos resumos eleitos e a terceira última fase de seleção, onde ocorreu finalmente a leitura dos trabalhos que forneciam subsídios ao estudo. Conclusão: Observa-se que na maioria dos artigos é relatado a crença em Deus baseada na fé e na espiritualidade, o que mostra que se trata de um apoio favorável, estimula as pessoas a curar o medo e a ansiedade e é fonte de força para os participantes das pesquisas encontradas.

Palavras- Chave: Espiritualidade, câncer, saúde pública.

\section{INTRODUÇÃO}

Este trabalho trata-se de uma revisão de literatura que abordam temas relacionados a um senso de conexão com um ser de natureza superior pelos portadores de câncer.

Ter diagnóstico de neoplasia gera um abalo imensurável na vida da pessoa. Para enfrentar o momento conflituoso causado pela notícia, os indivíduos com câncer empregam variadas ferramentas de enfrentamento, sobressaindo no presente trabalho a religiosidade e a espiritualidade, que prevalecem em boa parte das pessoas acometida por essa enfermidade.

Todas as concepções de doutrina atuam aliadas aos discursos, atos, cultos e rituais, bem como os demais modelos de demonstração religiosa, de forma que o processo de ensino-aprendizagem possa ser propagado através de gerações utilizando-se da educação e do conhecimento.

No Universo há uma vibração sutilíssima que transpõe tudo denominado de plano vibratório divino. Situado abaixo deste, está o plano monádico em que vibram as Mônadas ou Centelhas Divinas (PATORINI, 2010)

Contudo o contato com um ser de natureza superior dar-se-á através da vibração da centelha divina que habita nos seres humanos. Dessa forma em busca de barganhar 
algo positivo ao seu favor, o indivíduo procura a interligação mente-corpo-espírito, através de algo que denomina fé, energia cósmica ou luz interior, muitas vezes ligado à religiosidade.

Destarte, o homem resultante de uma Fagulha divina, com sua mente, que se particulariza num Espírito, busca o caminho da evolução, pois para adiantar-se, o Espírito plasma para si, por adensamento, uma personalidade (conjunto de intelecto, astral, etéreo, e físico denso).

Considerando o ser espiritual e sob o olhar da saúde, pode-se pensar a espiritualidade pautada no diálogo e em novas interpretações. Desta forma, emerge um tema a ser considerado que reflete na importância espiritual frente a uma doença, não mais apenas subdividindo o homem através do equilíbrio dinâmico mente e corpo, recomendado por Descartes.

Não obstante, a concepção holística foca na percepção do homem em sua plenitude distanciando-se assim desse simplicíssimo dicotomizado. Nesse sentido, deve-se consolidar interação entre espiritualidade, no âmbito da fé, situada no campo científico.

Espiritualidade é aquela maneira pela qual intuímos que uma Energia intensa, que titulamos Espírito Criador ou Deus, perpassa todos os indivíduos e os sustentam como um incomensurável sistema cheio de significado e de propósito (BOFF, 2010). É existir com espírito e, logo, é uma grandeza constitutiva do ser humano. Isto é, viver conforme a dinâmica intensa da vida. Com isso denota que tudo na essência é visto a partir de uma nova visão aonde o indivíduo vai edificando a sua integralidade e a sua conexão com tudo que o rodeia (MULLER, 2004)

No decorrer da vida o processo energético pode variar de acordo com sua consciência, que ligada à concentração, amplifica a capacidade do indivíduo de percepção interna e externa.

Entende-se por consciência a junção de tudo aquilo em que prestamos atenção. Alguns indivíduos desconcentram-se pelos impasses do dia a dia, circunstâncias 
negativas que, sozinhas, aparentam ser irrelevantes, porém, juntas, bastam para sobrecarregar a consciência (CHOPRA, 2019)

Destarte, uma pessoa em sua sã consciência, considerada normal, não pode ser persuadida de que o livre-arbítrio é inexistente, o universo opera em conformidade com as leis da física, contudo os indivíduos permanecem livres para fazer suas predileções (CHOPRA e MILODNOW, 2012)

O ato de concentração depende de uma mente calma, tranquila, onde a frequência de ondas cerebrais encontra-se em alfa e, estas por sua vez promovem um relaxamento corporal onde enzimas de reestruturação biológica e regenerações teciduais são liberadas.

O controle da mente é imperioso para a concentração, meditação, e compreensão do "EU”. Krishnamurti (1997, p.56) relata que

o que importa, naturalmente, é que cada um de nós possa achar um estado perene de libertação de todos os conflitos e das inúmeras reações que tanto caos produzem na mente; e então, talvez, com essa liberdade, venhamos a descobrir algo existente além da nossa mente; mas antes que possamos ser livres, temos, por certo, de compreender o que é o "eu". [...] se uma pessoa deseja realmente descobrir, por si própria, deverá lançar a base correta, e a base correta é a meditação. A base correta para se descobrir se existe uma realidade além das crenças que a propaganda inculcou na mente de cada um, essa base só pode ser criada pelo autoconhecimento. O conhecer a si mesmo é, exatamente, meditação. Conhecer a si mesmo não é conhecer o que se deveria ser, pois isso não tem validade, nem realidade, e não passa de mera ideia ideal.

O conhecimento de si mesmo e a espiritualidade são fontes essenciais para que possamos viver em completude, com autocontrole gerando a plenitude de sentimentos elevados na maior fração de tempo, corroborando desta forma, com uma evolução singular ao longo da vida e em todo seu contexto.

Coadunando Datolli (2017) ressalta que o devotamento ao autoconhecimento e a procura incessante de evolução espiritual, concerne variadas descobertas do "EU", dentre elas, os defeitos, limitações, barreiras, que são particularidades necessitam de 
aperfeiçoamento. Assim, chama atenção para a importância de se observar quanto ao ego e pensamentos individuais, alimentados pela sociedade em que vivem.

O ego é o responsável pelo sentido da consciência e direção da vida. A influência do meio em relação à troca de energia pode levar a desconexões energéticas entumecendo o corpo etéreo desfraldando em enfermidades refletidas no indivíduo, como gastrite, psoríase, câncer, dentre outras.

Perceber-se doente, em situações de desequilíbrio bio-psico-social, desperta no ser humano uma intensa e desesperadora vontade de aproximar-se de um ser de natureza superior a fim de barganhar sua cura, porém como relata Pastorini (2010, p.11)

A prece não pode, científica e matematicamente, atingir os planos que desejamos, porque estamos "dissintonizados". Não se trata de maldade ou "exigência" dos Espíritos superiores. Mas não chega a eles nossa prece. Da mesma forma que um rádio só de "ondas curtas" não pode captar os sinais das "ondas longas" e vice-versa. Cada um (a ciência o comprova experimentalmente) só pode comunicar-se com seus afins em vibração.

Diante do contexto, o objetivo do estudo pauta-se em uma revisão bibliográfica, buscando a relação de conexão "Eu-Deus" em pacientes portadores de câncer.

\section{MATERIAIS E MÉTODOS}

\section{CRITÉRIOS DE INCLUSÃO}

Utilizou-se como critérios de inclusão para análise estudos relacionados espiritualidade/religião de pacientes portadores de câncer, publicados entre 2015 e 2020 sem ressalvas de idade, sexo, etnia e afinidade religiosa, bem como sem restrição ao idioma de publicação.

\section{ESTRATÉGIA DE BUSCA}

As buscas foram realizadas a partir de publicações indexadas nas bases de dados Scielo, Lilacs e Medline, cruzando os termos: câncer/espiritualidade/saúde, 
cancer/spirituality/health e cáncer/espiritualidad/salud. A pesquisa foi limitada aos idiomas Inglês, Português e Espanhol, de 2015 a 2020, durante o período de setembro/2019 a junho/2020.

\section{SELEÇÃO DOS ESTUDOS}

Foram localizados 934 artigos dos quais sete investigações constituíram a seleção final por atender o objetivo do estudo. As análises para a seleção dos artigos ocorreram em três etapas distintas.

A primeira foi realizada pelas pesquisadoras, tendo como base os subsídios fornecidos pelo título e palavras-chave, onde após um busca minuciosa, foram descartados aqueles que não enquadravam-se no assunto pesquisado, encontravamse duplicados, os que apresentavam apenas resumos e os que embora no título constasse uma ou mais palavras da busca, apresentavam-se fora dos critérios de inclusão.

$\mathrm{Na}$ segunda, passou-se à leitura dos resumos eleitos com a temática que atendiam aos propósitos da investigação, ocorrendo mais descarte de material, que não traziam em seu conteúdo a finalidade da pesquisa, passando a terceira e última fase de seleção, onde ocorreu finalmente a leitura dos trabalhos que forneciam subsídios ao estudo.

Para melhor compreensão do processo de seleção para estudos incluídos na análise, foi realizado um esquema onde pode-se observar os passos realizados no exame dos artigos encontrados nas bases de dados pesquisadas (figura 01).

\section{Excluídos por resumo $(\mathrm{n}=110)$}

Fora dos critérios de inclusão: 98

Congressos e simpósios:12 
Artigos excluídos $(n=4)$

Fora dos critérios de inclusão

Artigos relevantes identificados para avaliação $(n=934)$ :

SciELO: 48

LILACS: 98

MEDLINE: 788

Artigos excluidos $(n=925)$ :

Duplicados $=85$

Por título $=730$

Por resumo $=110$

Artigos analisados por leitura do texto completo $(n=9)$ 
Artigos incluídos na revisão sistemática $(n=5)$

Figura 1. Processo de seleção para estudos incluídos na análise.

\section{ANÁLISE E DISCUSSÃO DOS DADOS}

Após a busca, a Tabela 1 traz os elementos das referências, seguindo a metodologia proposta. Para tanto, são fornecidas informações como autor, país, população, delineamento do estudo e local de seleção da amostra.

Tabela 1- Caracterização dos estudos incluídos na revisão de literatura

\begin{tabular}{|c|c|c|c|c|c|c|}
\hline \multirow[t]{2}{*}{ Autores } & \multirow{2}{*}{$\begin{array}{l}\mathrm{Pa} \\
\text { ís }\end{array}$} & \multicolumn{3}{|c|}{ População } & \multirow{2}{*}{$\begin{array}{l}\text { Delineam } \\
\text { ento do } \\
\text { estudo }\end{array}$} & \multirow[t]{2}{*}{ Local de seleção da amostra } \\
\hline & & n & $\begin{array}{l}\text { Ida } \\
\text { de } \\
\text { mé } \\
\text { dia } \\
\text { (an } \\
\text { os) }\end{array}$ & $\begin{array}{l}\text { Sex } \\
0\end{array}$ & & \\
\hline
\end{tabular}




\begin{tabular}{|c|c|c|c|c|c|c|}
\hline $\begin{array}{l}\text { MIRANDA, } \\
\text { Sirlene Lopes } \\
\text { de; LANNA, } \\
\text { Maria dos } \\
\text { Anjos Lara e; } \\
\text { FELIPPE, } \\
\text { Wanderley } \\
\text { Chieppe }\end{array}$ & $\begin{array}{l}\mathrm{Br} \\
\text { asi } \\
\mathrm{I}\end{array}$ & 5 & 55 & $\begin{array}{l}\text { F- } \\
66,7 \\
\% \\
M- \\
33,3 \\
\%\end{array}$ & $\begin{array}{l}\text { Explorató } \\
\text { ria }\end{array}$ & $\begin{array}{l}\text { Casa de Apoio aos Pacientes } \\
\text { com Câncer - Vencer }\end{array}$ \\
\hline $\begin{array}{l}\text { KUNZ, Josiane } \\
\text { Aparecida; } \\
\text { CONDE, Carla } \\
\text { Regiani; } \\
\text { LEMOS, Talita } \\
\text { Mayara Rossi; } \\
\text { BARROS, Ana } \\
\text { Elisa de } \\
\text { Sousa;FERREI } \\
\text { RA; Maria de } \\
\text { Lourdes da } \\
\text { Silva Marques. }\end{array}$ & $\begin{array}{l}\mathrm{Br} \\
\text { asi } \\
\mathrm{I}\end{array}$ & 1 & - & $\begin{array}{l}F- \\
100 \\
\%\end{array}$ & $\begin{array}{l}\text { Fenomen } \\
\text { ológica }\end{array}$ & $\begin{array}{l}\text { BOTUCCAM (Botucatu no Co } \\
\text { mbate ao Câncer de Mama) }\end{array}$ \\
\hline $\begin{array}{l}\text { BENITES, } \\
\text { Andréa } \\
\text { Carolina; } \\
\text { NEME, } \\
\text { Carmen Maria } \\
\text { Bueno; } \\
\text { SANTOS, } \\
\text { Manoel } \\
\text { Antônio dos. }\end{array}$ & $\begin{array}{l}\mathrm{Br} \\
\text { asi } \\
\mathrm{I}\end{array}$ & 0 & $\begin{array}{l}57 \\
5\end{array}$ & $\begin{array}{l}\text { F- } \\
50,0 \\
\% \\
M- \\
50,0 \\
\%\end{array}$ & $\begin{array}{l}\text { Fenomen } \\
\text { ológica }\end{array}$ & $\begin{array}{l}\text { Hospital São Judas } \\
\text { Tadeu/Hospital do Câncer de } \\
\text { Barretos }\end{array}$ \\
\hline
\end{tabular}




\begin{tabular}{|c|c|c|c|c|c|c|}
\hline $\begin{array}{l}\text { ALVARES, } \\
\text { Rafaella } \\
\text { Bortolassi; } \\
\text { SANTOS, } \\
\text { Izabel Dayana } \\
\text { de Lemos; } \\
\text { LIMA, Nara de } \\
\text { Morais; } \\
\text { MATTIAS, } \\
\text { Silvia Regina; } \\
\text { CESTARI, } \\
\text { Maria Elisa } \\
\text { Wotzasek; } \\
\text { GOMES, } \\
\text { Natália } \\
\text { Carolina } \\
\text { Rodrigues } \\
\text { Colombo; } \\
\text { PINTO, Keli } \\
\text { Regiane } \\
\text { Tomeleri da } \\
\text { Fonseca. }\end{array}$ & $\begin{array}{l}\mathrm{Br} \\
\text { asi } \\
\mathrm{I}\end{array}$ & 1 & 50 & $\begin{array}{l}\text { F- } \\
100 \\
0 \%\end{array}$ & $\begin{array}{l}\text { Descritiv } \\
0\end{array}$ & $\begin{array}{l}\text { Ambulatório de Oncologia do } \\
\text { Hospital Universitário Norte do } \\
\text { Paraná (HUNPR) }\end{array}$ \\
\hline $\begin{array}{l}\text { SORATTO, } \\
\text { Maria } \\
\text { Tereza; SILVA, } \\
\text { Dipaula } \\
\text { Minotto } \\
\text { da; ZUGNO, } \\
\text { Paula } \\
\text { loppi; DANIEL, } \\
\text { Raquel. }\end{array}$ & $\begin{array}{l}\mathrm{Br} \\
\text { asi } \\
\mathrm{I}\end{array}$ & 0 & 56 & $\begin{array}{l}\text { F- } \\
40,0 \\
\% \\
M- \\
60,0 \\
\%\end{array}$ & $\begin{array}{l}\text { Descritiv } \\
\text { a e } \\
\text { de campo }\end{array}$ & $\begin{array}{l}\text { hospital de grande porte e de } \\
\text { alta comple-xidade da Região } \\
\text { Sul de Santa Catarina. }\end{array}$ \\
\hline
\end{tabular}


A tabela 2 discorre sobre os títulos dos artigos e respectivos autores, seguidos dos resultados e ano de publicação, expondo a relevância dos estudos que fazem parte dessa revisão bibliográfica.

Tabela 2 -Descrição dos principais achados dos estudos identificados na revisão sistemática

\begin{tabular}{|c|c|c|}
\hline Autores/Tema & Resultados & Ano \\
\hline 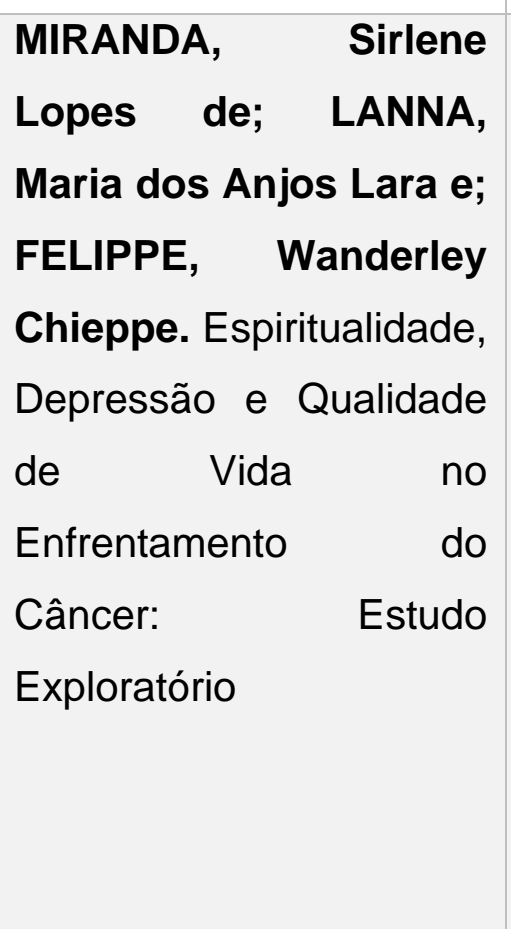 & $\begin{array}{l}\text { A população estudada apresentou bem- } \\
\text { estar espiritual e religioso moderados, o } \\
\text { que sugere que o câncer favorece a } \\
\text { busca pela espiritualidade e } \\
\text { religiosidade como mecanismos de } \\
\text { enfrentamento do sofrimento. As } \\
\text { correlações apontam para uma busca } \\
\text { significativa do paciente oncológico por } \\
\text { espiritualidade e melhora em sua } \\
\text { qualidade de vida. O apoio do cônjuge, } \\
\text { demais familiares, amigos e pessoas } \\
\text { religiosas constituem uma rede social de } \\
\text { apoio ao paciente oncológico. }\end{array}$ & 2020 \\
\hline 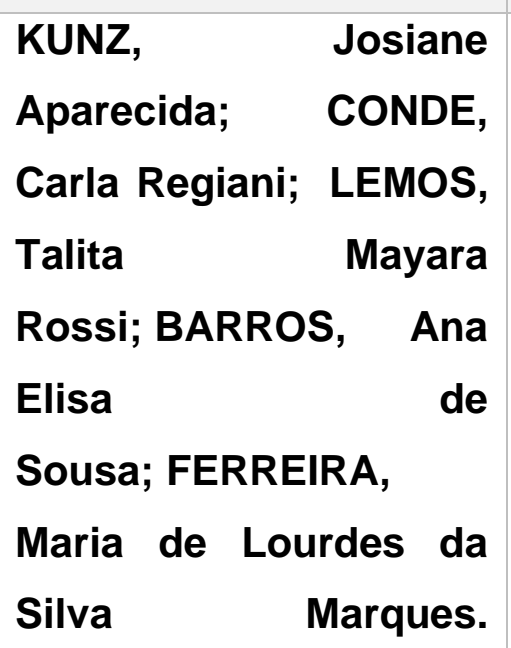 & $\begin{array}{l}\text { O câncer de mama afeta não só a } \\
\text { dimensão física das mulheres, mas os } \\
\text { aspectos emocionais, sociais } \\
\text { e familiares. Neste sentido, a } \\
\text { religiosidade e espiritualidade foram } \\
\text { alternativas buscadas pelas mulheres } \\
\text { para enfrentar a doença, enquanto a fé } \\
\text { proporcionou a esperança da cura. }\end{array}$ & 2018 \\
\hline
\end{tabular}


A Religiosidade e

Espiritualidade de

Mulheres com Câncer de

Mama Submetidas a

Tratamento Cirúrgico.
ALVARES,
Rafaella
O sentimento de fé em Deus, embasada
Bortolassi; SANTOS, em crenças e na espiritualidade, foram Izabel Dayana de relatadas em grande parte das Lemos; LIMA, Nara de entrevistas, demonstrando ser um Morais; MATTIAS, Silvia suporte favorável, um alento para sanar Regina; CESTARI, medos e angústias, e fonte de força para Maria Elisa Wotzasek; que as participantes da pesquisa GOMES, Natália pudessem encarar 0 diagnóstico, Carolina Rodrigues tratamento e todas as mudanças Colombo; PINTO, Keli geradas pela doença.
Regiane Tomeleri da Fonseca.
Sentimentos despertados nas mulheres frente ao diagnóstico de câncer de mama. 


\begin{tabular}{|c|c|}
\hline $\begin{array}{l}\text { SORATTO, Maria } \\
\text { Tereza; SILVA, Dipaula } \\
\text { Minotto da; ZUGNO, } \\
\text { Paula Ioppi; DANIEL, } \\
\text { Raquel. Espiritualidade e } \\
\text { resiliência em pacientes } \\
\text { oncológicos. }\end{array}$ & $\begin{array}{l}\text { Todos os pacientes entrevistados } \\
\text { consideram que existe influência da } \\
\text { espiritualidade na resiliência para } \\
\text { enfrentar o processo de adoecimento e } \\
\text { tratamento. A fé remove montanhas; } \\
\text { oferece força, suporte e sustentação } \\
\text { quando não conseguimos mais avançar. } \\
\text { Deus simboliza a superação diante da } \\
\text { crise existencial. }\end{array}$ \\
\hline
\end{tabular}

A literatura aborda formas de mecanismos de enfrentamento demonstrando como os portadores de câncer se apoiam e lidam ativamente com eles mesmos. Nessa perspectiva, os sujeitos vivenciaram uma nova etapa de adaptação, que além de mudanças físicas, alteram seus sentimentos e autoconhecimento, promovendo uma conexão com um Ser de Natureza Superior de maneira mais íntima. Outro enfoque é a importância de ser resiliência, pois que ela traz a capacidade de superar o tratamento, recuperar os obstáculos e surgirem a vida.

Diversas questões relacionadas à espiritualidade e crenças religiosas foram citadas, onde a fé, estabelecida e fortalecida na sociedade, é a responsável por reacender a esperança destes, uma vez que perpassam por uma série de preocupações sobre o câncer.

Por acreditarem na espiritualidade adotam uma relação de poder com Deus Ihes proporcionando o desejo de melhorar e até curar-se, por meio da oração. Essa intimidade com o Ser de Natureza Superior, diante da insegurança e da incerteza, resulta na construção do calor da alma, fazendo da fé o único ponto seguro e "palpável" no campo das imprevisibilidades causadas pelo câncer.

O indivíduo portador de câncer, entende a religião/espiritualidade como suporte nos momentos de sofrimento, o que se torna vital no doloroso tratamento da neoplasia. 
Pacientes que portam esta patologia, buscam os benefícios espirituais em seus tratamentos e muitas vezes veem os grupos religiosos como uma fonte de apoio, visto que este ambiente é propício para o compartilhar das emoções, das dores com eles, levando-os a sentirem-se confortados.

A comunicação com a Divindade através da oração, fortalece a fé, que por sua vez transcende pensamentos e crenças, amplifica o contato com o mundo interior e exterior, transmutando sua energia, minimizando o sofrimento, fornecendo subsídios para a sensação de felicidade, além de minimizar o desequilíbrio mental.

Ao refletir as práticas espirituais, observam-se aspectos importantes da vida dos portadores de câncer, visto que são compartilhados principalmente pelos pacientes em diferentes lugares, que refletem práticas culturais comuns, e por meio de usos e costumes.

Destarte, a espiritualidade através da conexão "eu-Deus" fornece suporte incomensurável para pacientes com câncer, proporcionando-lhes poder, que os libera do medo e angústias, e fortalece o autoconhecimento e a vivência na fé.

\section{CONSIDERAÇÕES FINAIS}

Observa-se que na maioria dos artigos é relatado a crença em Deus baseada na fé e na espiritualidade, o que mostra que se trata de um apoio favorável, estimula as pessoas a curar o medo e a ansiedade e é fonte de força para os participantes das pesquisas encontradas.

Observa-se também que o autoconhecimento é um caminho a ser seguido para ampliar a fé, a crença e a conexão com o Ser de Natureza Superior levando-os a evolução espiritual e ao controle das emoções.

Apesar das limitações da pesquisa, vale ressaltar que os resultados apresentados constituem religião e espiritualidade baseadas na fé e que Deus é fonte de força e esperança onde a cura, a graça e o milagre são atribuídos a Ele. 


\section{REFERÊNCIA BIBLIOGRÁFICA}

(OMS/WHO), Constituição da Organização Mundial da Saúde. 1946. http://www.direitoshumanos.usp.br/index.php/OMS-Organiza\%C3\%A7\%C3\%A3oMundial-da-Sa\%C3\%BAde/constituicao-da-organizacao-mundial-da-saudeomswho.html (acesso em 04 de 20 de 2020).

ALVARES, Rafaella Bortolassi, et al. "Sentimentos despertados nas mulheres frente ao diagnóstico de câncer de mama." Journal of Nursing and Health 7, № 3 (2020): e177309 (1-10).

BENITES, Andréa Carolina, NEME, Carmen Maria Bueno, e SANTOS, Manoel Antônio dos.. "Significados da espiritualidade para pacientes com câncer em cuidados paliativos." Estud. psicol. (Campinas) [online] 34, no 2 (2017): 269-279.

BOFF, Leonardo. Ciudar da terra, proteger a vida: como evitar o fim do mundo. Rio de Janeiro: Record, 2010.

CHAVES, Flávio Silva, e Francisco Assis Souza SANTOS. "A espiritualidade e a medicina integrativa no contexto da saúde integral do ser humano." Estudos Teológicos 57, no 2 (jul/dez 2017): 382-400.

CHOPRA, Deepack, e Leonard MILODNOW. Ciencia e espiritualidade: dois pensadores, duas visões de mundo. Vol. 1, em Ciencia e espiritualidade: dois pensadores, duas visões de mundo, por Deepack Chopra, edição: tradução Claudio Carina, 321. Rio de Janeiro: Zahar/Sextane, 2012.

CHOPRA, Deepak. As sete leis espirituais do sucesso. 74. Edição: Best Seller. Tradução: Vera Caputo. Rio de Janeiro: Best Seller, 2019.

DATTOLI, Clovis. Longevidade: Como se preparar para uma vida longa e bemsucedida. 1. Edição: Figurati. Barueri (SP): Figurati, 2017.

GILSON, E., BOEHNER, P. História da filosofia cristã: Desde as origens até Nicolau de Cusa. Petrópolis: vozes, 1988. 
KRISHNAMURTI, Juddu. Krihsnamurti, o libertador de mentes. 1. São Paulo: Martin Claret, 1997.

KUNZ, Josiane Aparecida, Carla Regiani CONDE, Talita Mayara Rossi LEMOS, Ana Elisa de Sousa BARROS, e Maria de Lourdes da Silva Marques FERREIRA. "A Religiosidade e Espiritualidade de Mulheres com Câncer de Mama Submetidas a Tratamento Cirúrgico." Rev. Enferm. Atual In Derme (edição especial N 86), 2018.

MIRANDA, Sirlene Lopes de, Maria dos Anjos Lara e LANNA, e Wanderley Chieppe. FELIPPE. "Espiritualidade, Depressão e Qualidade de Vida no Enfrentamento do Câncer: Estudo Exploratório." Psicol. cienc. prof. [online] 35 , № 3 (2015): 870-885.

MULLER, Marisa Campio. "Espiritualidade e qualidade de vida." Em Espiritualidade e qualidade de vida, por Evilázio Francisco Borges Teixeira. Porto Alegre: EDIPUCRS, 2004.

PASTORINO, C. T. Técnica da mediunidade. 2ª . Sabedoria, 2010.

SORATTO, Maria Tereza, Dipaula Minotto da SILVA, Paula loppi ZUGNO, e Raquel. DANIEL. "Espiritualidade e resiliência em pacientes oncológicos." Saude e Enviado: Outubro, 2020.

Aprovado: Novembro, 2020. 